\section{Prevalence of asymptomatic neurophysiological carpal tun- nel syndrome in 130 healthy individuals}

\author{
Omar Alrawashdeh \\ Clinical Neurology, Faculty of Medicine, \\ Mutah University, Mutah, Jordan
}

\begin{abstract}
Diagnosis of carpal tunnel syndrome (CTS) is frequently confirmed by performing nerve conduction studies. Previous studies demonstrated that abnormal nerve conduction study (NCS) is suggestive of CTS among asymptomatic individuals. However, previous studies included individuals with risk factors for the syndrome. A NCS was performed on the median and ulnar nerves in 130 healthy individuals. About $15 \%$ of individuals in this study demonstrated electrodiagnostic evidence of carpal tunnels syndrome. Four cases have shown signs of isolated median neuropathy with normal median sensory component. Results indicated that the most widely used method for confirming diagnosis of CTS may have up to $15 \%$ of false positives. However, most of those showed changes of minimal CTS. Isolated prolongation of the median motor latency should be investigated further as they are usually classified as moderate to severe CTS and may undergo unnecessary surgeries.
\end{abstract}

\section{Introduction}

The median nerve is a mixed sensory and motor nerve. It passes in the forearm between the biceps and the brachialis. The nerve passes in the cubital fossa and gives a branch to pronator teres and two branches in the forearm for muscles in the anterior compartment of the forearm. ${ }^{1}$ The nerve passes the wrist through the carpal tunnel along with tendons of long flexors of the fingers then splits into digital branches and muscular branches. The digital branches supply the skin of the thumb, the index, the middle, and the radial side of the ring finger, while the muscular branch supplies the thenar muscles and part of the lumbricals. ${ }^{2}$

The median nerve is commonly compressed where is passes in the carpal tunnel. The condition is therefore called carpal tunnel syndrome (CTS), which is the most common form of nerve entrapment. Regardless of the risk factors, the prevalence of the disease in general population is about $15 \% .{ }^{3} \mathrm{CTS}$ is a common disabling disorder and accounts for $90 \%$ of all entrapment neuropathies. ${ }^{4}$ It usually interferes with the daily activities and may result in absence from work. In 1995, the estimated cost of CTS in the USA was 2 billion US dollars. There were 500,000 carpal tunnel releases in the US in 2006.5

Diagnosis of CTS is established clinically and frequently confirmed by performing nerve conduction study (NCS). The most commonly used NCS abnormality that confirms the presence of CTS is the comparison between the latencies of the median and the ulnar nerves on the same hand. Severity of CTS usually classified according to results obtained from the NCS which reflects the degree of demyelination and axonal loss in the median nerve. ${ }^{6}$ There are a number of risk factors of CTS including thyroid disease, ${ }^{7}$ diabetes mellitus, obesity, ${ }^{8}$ rheumatoid arthritis, and pregnancy. ${ }^{9}$ Other important risk factors are occupational. The first description of occupational factors in developing CTS was in 1947.10 The physical factors that underlie occurrence of CTS include repetition, sustained flexion, and vibration around the wrist joint. Repetitive movement of the wrist remains the most important occupational factor involved in developing CTS.11,12

Asymptomatic individuals with electrodiagnostic evidence of CTS seem to have tendency to develop CTS later in life more than others with normal NCS. 13 Therefore, pre-employment screening for CTS has been suggested to identify individuals with risk of CTS in the future. However, most of the applied preemployment screening models were not cost effective. ${ }^{14,15}$ Better data collection with appropriate change in work circumstances may reduce the incidence CTS and thus reduce the treatment cost. Therefore, it is important to identify the prevalence of electrodiagnostic CTS in asymptomatic individuals who do not carry any of the known risk factors for CTS. The study will address the percentage of false positives associated with the currently used NCS method. This may direct future research in improving diagnostic criteria and possibly in identifying new risk factors for the disease.

\section{Materials and Methods}

The study was conducted between 2014 and 2015 at the neurophysiology unit of one of the hospitals in the south of Jordan. Individuals included in the study were free of CTS symptoms such as pain, numbness, burning sensation, itching, or weakness at any area of the median nerve or ulnar nerve distribution. None of the participants had diabetes mellitus or hypothyroidism. All participants had body mass index (BMI) less than 25 with no history
Correspondence: Omar Alrawashdeh, Clinical Neurology, Faculty of Medicine, Mutah University, Mutah, Jordan.

E-mail: omar.smr@hotmail.com

Key words: Nerve conduction study; Carpal tunnel syndrome; Asymptomatic.

Acknowledgments: the author would like to thank all physicians and nurses at the Faculty of Medicine in Mutuh University and Alkarak Hospital in Alkarak/Jordan for their help and support.

Conflict of interest: the author declares no potential conflict of interest.

Received for publication: 21 April 2016.

Revision received: 5 June 2016.

Accepted for publication: 5 June 2016.

This work is licensed under a Creative Commons Attribution NonCommercial 4.0 License (CC BYNC 4.0).

(C) Copyright O. Alrawashdeh, 2016

Licensee PAGEPress, Italy

Neurology International 2016; 8:6553

doi:10.4081/ni.2016.6553

of upper limb fractures or significant trauma. Female patients who were pregnant or taking oral contraceptive pills were not included in the study. All participants of the study have occupations that do not include working with vibrating tools or require prolonged and repetitive fingers and wrist flexion.

A number of 130 previously healthy individuals of both sexes were involved in the study (84 females and 46 males). The age ranged from 20 to 70 years for males (mean \pm standard deviation $=43 \pm 11.80$ years) and 16 to 66 form females $(40 \pm 10.60)$. For the entire sample, the minimum body mass index was 18.6 and the maximum was 25 (mean=21.81 $\pm \mathrm{SD}=1.91$ ). The study has been approved by the local research ethics committee.

\section{Nerve conduction study}

A NCS was performed on the right hand of every participant. The procedure included examination of the median nerve and the ulnar nerve. Measurements obtained were the sensory peak latencies at $14 \mathrm{~cm}$ and onset motor latencies at $8 \mathrm{~cm}$ of both nerves. The study also obtained both nerves compound action potential (CMAP), sensory nerve action potential (SNAP), and the conduction velocity of the motor median nerve at the forearm segment.

Diagnosis of subclinical CTS was established based on the previously accepted measures. Relative prolongation of the peak distal 
sensory latency of the median nerve compared to that of the ulnar nerve was considered for the diagnosis of CTS. A difference of $\geq 0.5 \mathrm{~ms}$ in the sensory latency was considered positive for the diagnosis of asymptomatic CTS. 16,17

\section{Results}

\section{The peak sensory latency}

The mean peak sensory latency of the median nerve was $3.21 \mathrm{~ms}$. This latency was $3.26 \mathrm{~ms}$ in females and $3.12 \mathrm{~ms}$ in males $(\mathrm{P}=0.055)$. The mean peak sensory latency of the ulnar nerve was $2.89 \mathrm{~ms} \pm \mathrm{SD}=0.35 \mathrm{~ms}$. The mean ulnar latency was 2.81 in males and 2.91 in females $(\mathrm{P}=0.164)$.

\section{Motor latency}

The mean onset latency of the median nerve was $3.55 \mathrm{~ms} \pm \mathrm{SD}=0.32$. In males the latency was 3.46 and in females was $3.60 \mathrm{~ms}$ $(\mathrm{P}=0.027)$. The mean onset latency of the ulnar nerve was $2.82 \pm 0.31 \mathrm{~ms}$. In males the mean latency was $2.75 \mathrm{~ms}$ and in females was $2.85 \mathrm{~ms}(\mathrm{P}=0.08)$.

\section{Motor compound action potential}

The median CMAP amplitude ranges between 2.4 to 7.8 millivolts (Mv) with a mean of $5.66 \pm 1.03 \mathrm{mV}$. In females the amplitude was $5.7 \mathrm{mV}$ and in males the amplitude was $5.6 \mathrm{mV}$ $(\mathrm{P}=0.6)$. The ulnar CMAP ranged between 4.30 $\mathrm{mV}$ to $9.70 \mathrm{mV}$ with a mean of $6.92 \pm 1.3 \mathrm{mV}$. In females the ulnar amplitude was $7.02 \mathrm{mV}$ and in males the amplitude was $6.74 \mathrm{mV}(\mathrm{P}=0.24)$.

\section{Sensory action potential}

The median SNAP amplitude of the median nerve was $40.42 \pm 13.51$ microvolt $(\mathrm{uV})$. In females the amplitude was $41.37 \mathrm{uV}$ and in males the amplitude was $38.72 \mathrm{uV}(\mathrm{P}=0.29)$. The mean ulnar SNAP amplitude was $34.10 \pm 10.65 \mathrm{uV}$. In females the ulnar SNAP amplitude was $34.31 \mathrm{uV}$ and in males was $33.70 \mathrm{uV}(\mathrm{P}=0.76)$.

\section{Nerve conduction velocity}

The mean median motor conduction velocity at the forearm was $55.43 \pm 6.25 \mathrm{~m} / \mathrm{s}$. The conduction velocity in males was $55.6 \mathrm{~m} / \mathrm{s}$ and 55.2 $\mathrm{m} / \mathrm{s}$ in females.

\section{Neurophysiological carpal tunnel syndrome}

There were 21 subjects who demonstrated neurophysiological evidence of asymptomatic CTS, i.e. median sensory peak latency that is slower than the ulnar sensory peak latency by $0.5 \mathrm{~ms}$ or more. Number of females was 15 and forms $18 \%$ of the females. Number of males was 5 and this forms $11 \%$ of males. There was no difference between the two groups (male and females) in the percentage of asymptomatic CTS (Chi square $0.51, \mathrm{P}=0.48$ ). Out of the 21 subjects with asymptomatic CTS, 10 individuals showed borderline prolongation at $0.5 \mathrm{~ms}$. This means that about $50 \%$ would be diagnosed as very mild CTS according to previously published grading scale. ${ }^{6}$ There was no difference in the mean age between those with normal NCS and those with asymptomatic CTS. The mean age of individuals with asymptomatic CTS was 43 years and those with normal NCS were 41 years.

There were 14 participants with median motor onset latency slower than that of the ulnar nerve by $\geq 1 \mathrm{~ms}$. Number of females was 11 forming $13 \%$ of females and number of males was 3 forming $6 \%$ of males which did not show statistical significance (Chi square 0.92, $\mathrm{P}=0.34$ ). Results showed that individuals with prolonged motor latency tend to have lower median CMAP. The mean median CMAP amplitude of individuals with prolonged motor latency was $4.68 \mathrm{mV}$ while the mean median CMAP of the rest of individuals was $5.78 \mathrm{mV}$ $(\mathrm{P}=0.006)$.

\section{Discussion}

\section{The nerve conduction normal values}

The study has explored the ulnar and median NCS values in 130 healthy patients. The examined values were the motor onset latencies at $8 \mathrm{~cm}$ distance, the sensory latencies at $14 \mathrm{~cm}$ distance, the CMAP, the SNAP, and the conduction velocity of the median nerve forearm segment. According to the previously published studies, values reported in this study were similar to previously published data. 18

\section{Prevalence of asymptomatic carpal tunnel syndrome}

CTS is characterized by compression of the median nerve at the wrist leading to sensory symptoms at the distribution of the median nerve. However, sensory symptoms such as numbness or neuropathic pain do not correlate significantly with the diagnosis of CTS. About 1 of 5 patients with numbness of the hand is expected to have CTS. ${ }^{3}$ In another occasion, de Krom has reported that the diagnostic value of nocturnal paraesthesia of the hands is approximately $38 \% .{ }^{19}$ Diagnosis of CTS is therefore frequently confirmed by performing neurophysiological studies.

Different neurophysiological approaches have been applied to diagnose CTS. A number of protocols have been reviewed by Werner 2010 and Jablecki 1993.20,21 Compression of the nerve initially causes local ischemia and consequently loss of the myelin around the axons. This results in focal slowing of the conduction of the action potential. Therefore, the most widely used NCS techniques aim at confirming focal slowing of the median nerve at the wrist segment. The sensory axons are the first to be affected because they are large myelinated fibers with high metabolic demand $^{22}$ and thus the most sensitive method for CTS diagnosis is the comparison of the sensory median latency to the ulnar sensory latency in the same individual and the same hand.20,21 Such comparison usually eliminates effects of individual variation and tissue temperature at time of the study. ${ }^{20,22}$

Diagnosis of CTS is usually considered if the median peak sensory latency was $\geq 0.5 \mathrm{~ms}$ greater than that of the ulnar nerve. This has been applied in this study and accordingly demonstrated that 21 individuals showed prolonged distal sensory latency of the median nerve compared to the ulnar nerve of the same hand. This means that $15 \%$ of asymptomatic participants, who do not carry any of the known risk factors for CTS, demonstrate electrodiagnostic evidence of CTS.

In 1999, Atroshi studied the prevalence of CTS in normal population. About $18 \%$ of asymptomatic participants demonstrated neurophysiological results suggestive of CTS. ${ }^{3}$ This is approximately similar to results obtained from the present study. However, unlike our study, Atroshi and colleagues did not exclude individuals with risk factors for CTS, which may explain the slightly lower percentage in this study.

In this study, 10 participants of the 21 patients had a borderline prolongation of the median sensory latency ( 0.5 greater than the ulnar nerve). This implies that the marginal 0.5 difference has the greatest number of false positives. Percentage of false positives is expected to be higher in other individuals who carry any of the risk factors for CTS and thus those individuals may have different normalized values. For example, active workers were found to have normally greater difference in sensory latencies between the median and ulnar nerves. Salmero and colleagues suggested that the difference in sensory latency should be more than $0.8 \mathrm{~ms}$ to confirm CTS diagnosis in active workers. ${ }^{23}$ Similarly, Alber and colleagues studied patients with mild DM and reported that a difference of more than 1 ms in the sensory latency is essential to confirm CTS diagnosis in patients with mild DM. ${ }^{24}$

Although, involvement of the motor component of the median nerve has limited diagnostic value in CTS, it is sometimes considered for the diagnosis of MS. For the motor latency, the marginal abnormal difference to diagnose CTS is usually $1 \mathrm{~ms}^{25}$ and sometimes $1.5 \mathrm{~ms}^{20}$ However, motor latency is more helpful in indicating severity of CTS. This is because long- 
standing median nerve compression progress to demyelination of the smaller motor axons leading to prolongation of the motor onset latency in more advanced cases of CTS.

In this study, there were 14 patients with prolonged motor latency of more than $1 \mathrm{~ms}$ compared to the ulnar motor latency. There was only 1 individual with median motor latency delayed by $1.5 \mathrm{~ms}$ compared to that of the ulnar nerve. There were 4 individuals with isolated prolongation of the motor latency without evidence of median peak sensory prolongation. Therefore, involvement of median motor neuropathy in the diagnosis of CTS may increase the number of false positives. Isolated prolonged onset motor latency in those individuals can be part of a condition called median motor mononeuropathy, where CTS is one of the causes of this condition.26,27 With prolonged demyelination, axon may undergo degeneration. This usually leads to conduction block or may develop to axonal loss, which is demonstrated by a drop in the sensory and/or the motor amplitudes. In advanced cases, atrophy of the muscles supplied by the median nerve may occur. There were 17 participants forming $13 \%$ of the sample who demonstrated reduction in the median CMAP below $4.5 \mathrm{mV}$. On examination of those subjects, none of them has shown weakness or apparent atrophy of thenar muscles. The study has a number of limitations in that number of participants may not be enough to reflect the general population. The NCS procedures have been carried out at a number of occasions at different seasons and there were no records of the hand temperature or room temperature at time of examination. It is possible that not all of the involved individuals are risk free of CTS; for example, evaluation of risk factors depended on patient history and not on subjective assessment and there were no details of the type of participant's daily work and number of working hours.

\section{Conclusions}

In spite of the previously mentioned limitations of this study, results obtained may indicate that up to $15 \%$ of asymptomatic individuals demonstrate electrodiagnostic signs of CTS. Since most of individuals were at the 0.5 borderline, considering a $0.6 \mathrm{~ms}$ sensory latency difference in healthy individuals with no risk factors may reduce number of false positives. In addition, isolated prolongation of the median motor latency should be investigated further before establishing diagnosis of CTS.

\section{References}

1. Pandey SK, Shukla VK. Anatomical variations of the cords of brachial plexus and the median nerve. Clin Anat 2007;20:1506.

2. Wertsch JJ, Melvin J. Median nerve anatomy and entrapment syndromes: a review. Arch Phys Med Rehabil 1982;63:623-7.

3. Atroshi I, Gummesson C, Johnsson R, et al. Prevalence of carpal tunnel syndrome in a general population. Jama 1999;282:153-8.

4. Aroori S, Spence RA. Carpal tunnel syndrome. Ulster Med J 2008;77:6-17.

5. Palmer DH, Hanrahan LP. Social and economic costs of carpal tunnel surgery. Instr Course Lect 1995;44:167-72.

6. Bland JD. A neurophysiological grading scale for carpal tunnel syndrome. Muscle Nerve 2000;23:1280-3.

7. Palumbo CF, Szabo RM, Olmsted SL. The effects of hypothyroidism and thyroid replacement on the development of carpal tunnel syndrome. J Hand Surg Am 2000;25:734-9.

8. Karpitskaya Y, Novak CB, Mackinnon SE. Prevalence of smoking, obesity, diabetes mellitus, and thyroid disease in patients with carpal tunnel syndrome. Ann Plast Surg 2002;48:269-73.

9. Stolp-Smith KA, Pascoe MK, Ogburn PL Jr. Carpal tunnel syndrome in pregnancy: frequency, severity, and prognosis. Arch Phys Med Rehabil 1998;79:1285-7.

10. Brain WR, Wright AD, Wilkinson M. Spontaneous compression of both median nerves in the carpal tunnel; six cases treated surgically. Lancet 1947;1:277-82.

11. Cannon LJ, Bernacki EJ, Walter SD. Personal and occupational factors associated with carpal tunnel syndrome. J Occup Med 1981;23:255-8.

12. Silverstein BA, Fine LJ, Armstrong TJ. Occupational factors and carpal tunnel syndrome. Am J Ind Med 1987;11:343-58.

13. Werner RA, Gell N, Franzblau A, Armstrong TJ. Prolonged median sensory latency as a predictor of future carpal tunnel syndrome. Muscle Nerve 2001;24:1462-7.

14. Evanoff B, Kymes S. Modeling the costbenefit of nerve conduction studies in preemployment screening for carpal tunnel syndrome. Scand J Work Environ Health 2010;36:299-304.

15. Pransky G, Long R, Hammer $\mathrm{K}$, et al. Screening for carpal tunnel syndrome in the workplace. An analysis of portable nerve conduction devices. J Occup Environ Med 1997;39:727-33.
16. Kodama M, Tochikura M, Sasao Y, et al., What is the most sensitive test for diagnosing carpal tunnel syndrome? Tokai J Exp Clin Med 2014;39:172-7.

17. Uncini A, Lange DJ, Solomon M, et al., Ring finger testing in carpal tunnel syndrome: a comparative study of diagnostic utility. Muscle Nerve 1989;12:735-41.

18. Shahabuddin S, Badar DS, Moizuddin KM, et al. Normative values for nerve conduction study among healthy subjects from Aurangabad, INDIA. IJRTST 2013;8:56-61.

19. de Krom MC, Knipschild PG, Kester AD, et al., Carpal tunnel syndrome: prevalence in the general population. J Clin Epidemiol 1992;45:373-6.

20. Werner RA, Andary M. Electrodiagnostic evaluation of carpal tunnel syndrome. Muscle Nerve 2010;44:597-607.

21. Jablecki CK, Andary MT, So YT, et al., Literature review of the usefulness of nerve conduction studies and electromyography for the evaluation of patients with carpal tunnel syndrome. AAEM Quality Assurance Committee. Muscle Nerve 1993;16:1392-414.

22. Werner RA, Andary M. Carpal tunnel syndrome: pathophysiology and clinical neurophysiology. Clin Neurophysiol 2002;113: 1373-81.

23. Salerno DF, Werner RA, Albers JW, et al., Reliability of nerve conduction studies among active workers. Muscle Nerve 1999;22:1372-9.

24. Albers JW, Brown MB, Sima AA, Greene DA. Frequency of median mononeuropathy in patients with mild diabetic neuropathy in the early diabetes intervention trial (EDIT). Tolrestat Study Group For Edit (Early Diabetes Intervention Trial). Muscle Nerve 1996;19:140-6.

25. Sander HW, Quinto C, Saadeh PB, Chokroverty S. Sensitive median-ulnar motor comparative techniques in carpal tunnel syndrome. Muscle Nerve 1999;22:88-98.

26. Mondelli M, Aretini A, Ginanneschi F, Padua L. Thenar motor neuropathy electrophysiological study of 28 cases. J Clin Neurophysiol 2010;27:344-9.

27. Shams OE, Al-Ghamdi SM. Isolated neuropathy of the recurrent motor branch of the median nerve. Neurosciences (Riyadh) 2006;11:326-8. 